\title{
Oral health parameters in the regional study among young seniors in an urban area of Wrocław
}

\section{Wykładniki zdrowia jamy ustnej w regionalnym badaniu młodych seniorów miejskiego rejonu Wrocławia}

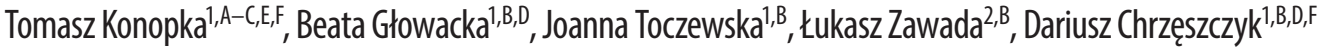 \\ ${ }^{1}$ Department of Periodontology, Wroclaw Medical University, Poland \\ ${ }^{2}$ Private Practice, Oława, Poland \\ A - research concept and design; $\mathrm{B}$ - collection and/or assembly of data; $\mathrm{C}$ - data analysis and interpretation; \\ $\mathrm{D}$ - writing the article; $\mathrm{E}$ - critical revision of the article; $\mathrm{F}$ - final approval of the article
}

Address for correspondence

Dariusz Chrzęszzzyk

E-mail: darek.chrzeszzzyk@interia.eu

\section{Funding sources}

This study was supported by statutory source of Department of Periodontology, Wroclaw Medical University.

Conflict of interest

None declared

Received on September 11, 2017

Reviewed on 0ctober 1, 2017

Accepted on November 7, 2017
DOI

10.17219/dmp/79850

Copyright

() 2017 by Wroclaw Medical University

and Polish Dental Society

This is an article distributed under the terms of the

Creative Commons Attribution Non-Commercial License

(http://creativecommons.org/licenses/by-nc-nd/4.0/)

\begin{abstract}
Background. Regional cross-sectional surveys are a vital addition to nationwide epidemiological studies. They are characterized by greater intensification of risk factors distribution, and the conclusions drawn therefrom are better suited to local gerostomatological treatment needs.

Objectives. The aim of the study was to examine young seniors (aged 65-74) in the Wrocław urban area and to assess the number of teeth, the prevalence of caries and periodontitis, as well as clinical lesions in oral mucosa. Also, the aim was to confirm the influence of local and general classical risk factors associated with these pathologies.
\end{abstract}

Material and methods. The following indexes were assessed: PI, API, BoP, PD, CAL, DMFT index and its components, number of teeth and occlusal supporting zones. CPI index was assessed based on periodontal examination, and then a periodontal diagnosis was given if present pathological lesions were noted.

Results. The average number of remaining teeth is 13.2 in the entire study group, the proportion of subjects with edentulism is $14.1 \%$. DMFT index amounts to 17.45 , and the percentage of people with periodontitis is $42 \%$, including $18.9 \%$ with a severe form. The study has revealed a very high prevalence of treated hypertension (almost half of the subjects) and cardiovascular diseases, very high prosthetic needs for more than $70 \%$ of subjects, and very poor oral hygiene: only $20 \%$ of subjects brush their teeth correctly, and only $7 \%$ clean their interdental spaces. A significantly higher prevalence of dental caries and higher periodontal exponents have been found in men. It has been shown that current tobacco dependence had a significant negative impact on the reduction of the number of teeth and severity of periodontitis. Socioeconomic factors had the biggest impact upon the number of remaining teeth and oral hygiene.

Conclusions. The study has shown an increase in the remaining teeth number in young seniors of Wrocław, despite the absence of a notable improvement in the incidence of dental caries and periodontitis, and it has also confirmed a significant influence of classical risk factors related to tooth loss and periodontitis.

Key words: periodontitis, epidemiology, periodontitis prevalence, tooth loss

Słowa kluczowe: zapalenie przyzębia, epidemiologia, występowanie zapaleń przyzębia, utrata zębów 
The theory of demographic transition, formed at the end of the $20^{\text {th }}$ century, emerged from profound changes in $\mathrm{Eu}$ rope's post-industrial societies in the sphere of values, standards, behaviors, and attitudes, leading primarily to a decline in the willingness to marry, a tendency to marry later in life, a decrease in the number of children in a family, and a trend to bear children later in life. The consequence of the so-called second demographic transition is a decline in birth rate, a decrease in population or - at least - a stabilization of the population, a distinct change in the age structure, with a tendency for a decline in the workingage population, faster aging of societies, and prolonged life span. In Europe, the proportion of people over 65 years of age is currently around $16.4 \%$, and it is estimated to reach $27.6 \%$ in $2050 .{ }^{1}$ In Poland, the percentage of people over the age of 65 accounted for $15.5 \%$ in 2015, and it is estimated that in 2050 this proportion may reach $26.9 \%{ }^{2}$ These changes involve an increased interest in many aspects of the health of the elderly, including the evaluation of oral health indicators and the determination of gerostomatological treatment needs. Epidemiological studies reveal that main oral pathologies in the elderly are tooth loss, tooth decay, periodontitis, and oral pre-cancer and cancer lesions. ${ }^{1}$ In 2010, the disability-adjusted life years (DALYs) per capita index for different regions of the world shows highest values for all oral conditions for Eastern (357) and Central Europe (334), and its global values related to dental conditions are highest for severe periodontitis (108), severe (less than 10) tooth loss (106) and untreated dental caries (73). ${ }^{3}$ For the elderly in developing countries, however, the main dental problem is tooth loss and the need for prosthetic treatment. An analysis of a 20-year trend for most world countries indicates a $45 \%$ reduction in the prevalence of tooth loss with the peak in incidence remaining around the age of $65 .{ }^{4}$ Still, these positive changes affect Eastern Europe in the slightest degree. In Europe, 3 countries with the highest average number of teeth in the elderly exceeding 20 is Sweden - 24.5, Denmark - 22.4, and Switzerland $-22.2 .^{5}$ Therefore, one of the WHO's announced objectives regarding the presence of more than 20 teeth in 80-yearold people is met only in these 3 countries. The lowest proportion of edentulism in the 65-74 age group also occurs in these 3 countries: Sweden $-2.7 \%$, Switzerland $-6.7 \%$, and Denmark $-6.8 \%$; and the highest is reported for the Czech Republic - 18.7\%, Slovenia - 19.2\%, and the Netherlands $-27.6 \%$ (the comparative analysis is based on data from 15 countries, excluding Poland). ${ }^{5}$ The varying numbers of remaining teeth reflect rather national differences in the focus of oral health care between prevention and repair. This assessment stems from the fact that there are no significant changes in the global prevalence and incidence of dental caries and periodontitis, which are the main medical causes of tooth loss. ${ }^{6-8}$ The prevalence and incidence of untreated dental caries in older patients has remained unchanged over the past 20 years, with the third peak of incidence around the age of 70 . This is partly due to the occur- rence of dental root caries at this age. The incidence peak for periodontitis occurs about the age of 38, and the prevalence of severe periodontitis reaches its maximum around the age of 40, and then it remains stable. ${ }^{6,7}$ The loss of connective tissue attachment, progressing with age, causes the proportion of pathological changes in the elderly's periodontium to remain at a high level (especially if we apply the definition of periodontal inflammation, taking into account this parameter), leading to gum recession in a greater degree rather than to generalized new cases of severe periodontitis. The majority of the elderly suffer from persistent, localized and moderate forms of periodontitis, because the most severe forms cause tooth loss usually between the ages of 40 and 60 . Attention should be paid to the methodological shortcomings of the CPI previously used in epidemiological studies among the elderly in Europe (underestimation of real prevalence and the extent of periodontal inflammation). Therefore, in modern studies, it is vital to determine both pocket depth and loss of attachment. In an epidemiological examination of an elderly patient's oral health, it is necessary to assess the clinical pathology of the mucous membrane, in particular pre-cancerous and cancerous lesions. They are not frequent, but they can have catastrophic individual consequences, especially in people with synergistic effects of nicotine and heavy alcohol abuse or with an infection caused by oncogenic forms of human papillomavirus (HPV).

All of the most common oral pathologies in the elderly have a multifactorial etiology. The level of epidemiological examination allows for the assessment of the influence of local factors, oral hygiene or health promotion and general behaviors, smoking, obesity, selected systemic diseases, and social and economic conditions. Particularly interesting are the two-way relationships between systemic pathologies frequent at this age (diabetes, obesity and metabolic syndrome) and oral health. Confirming the real impact of general and/or local factors allows for applying more causal and personalized multi-specialist action by, for instance, eradicating smoking or establishing the metabolic control of diabetes, as well as using the risk assessment tool. ${ }^{9}$

Attention is drawn by significant differences in the global prevalence of edentulism, number of remaining teeth, morbidity, and incidence of dental caries and periodontitis. In 2010, severe periodontitis ranged from $4.5 \%$ reported for the population of Oceania, to $20.4 \%$ reported for inhabitants of Southern Latin America. ${ }^{6}$ These differences may be substantial, even within a country; for instance, the fourth German Dental Health Survey of 2005 shows that differences in the number of teeth between seniors aged 65-74 years from the western and eastern Länder were 14.1 vs 12.5, respectively. ${ }^{10}$ Therefore, a representative regional research is a valuable supplement to a nationwide epidemiological research. Regional research is characterized by less diversified distribution of risk factors such as social and economic ones, and conclusions derived therefrom are more suited to local gerostomatological treatment needs. 
The aim of this cross-sectional epidemiological study of the inhabitants of Wrocław aged 65 to 74 years is to evaluate the number of remaining teeth and related prosthodontic treatment needs, assess the prevalence of dental caries and periodontal disease as well as lesions in oral mucous membrane, and to confirm the influence of local classical risk factors associated with these pathologies. The findings regarding the examined population will also be compared with the contemporary Polish and European regional epidemiological studies on the oral health of young seniors.

\section{Material and methods}

The study was conducted in Wrocław (Department of Periodontology, Wroclaw Medical University) and in Oława, a town located $40 \mathrm{~km}$ from Wrocław, with 35,000 inhabitants (private dental practice in Oława). At the Ministry of the Interior and Administration in Warszawa, a group of 1,000 people aged 65-74 years was randomly selected for Wrocław by means of a two-tier drawing method, and a group of 600 people was randomly selected for Oława in the same way. Therefore, a total of 1,600 inhabitants of Wrocław region were selected, with a symmetrical age and gender structure. The project leader invited (by letter and, if possible, by phone) the persons drawn to take part in the study at their own convenience. In the period between June $25^{\text {th }} 2017$ and August $1^{\text {st }} 2017$, 256 inhabitants of Wrocław (response rate 25.6\%) and 77 inhabitants of Oława (response rate 12.8\%) responded to the invitation. These persons submitted their written consent to participate in the study and to data processing by signing statements approved by the Bioethics Committee of Wroclaw Medical University (approval number 481/2013). The applied exclusion criteria for periodontal examination were as follows: general contraindications (e.g., the history of bacterial endocarditis) and local contraindications (e.g., acute odontogenic infection).

The examination was performed in artificial lighting, with the use of a dental mirror and WHO-621 periodontal probe. On one side the probe was marked with $1 \mathrm{~mm}$ sections, on the other side it was marked at $3.5 \mathrm{~mm}$, from 3.5 to $5.5 \mathrm{~mm}, 8.5$ and $11.5 \mathrm{~mm}$, and had a $0.5 \mathrm{~mm}$ sphere end. The collected data was archived in the epidemiological research form used in previous surveys commissioned by the Ministry of Health in the years 2013-2014. ${ }^{11}$

The following information was obtained in the interviews: age, education (primary, intermediate, higher), income per family member (up to 800 PLN, 801-1,500 PLN, 1,501-2,500, and over 2,500 PLN), nicotine addiction (never smoked - person who never smoked or have smoked less than 100 cigarettes; former smoker - persons who used to smoke at least 1 cigarette a day, currently not smoking and the abstinence period is longer than 365 days; current smoker - person who smoke at least 1 cigarette a day and person who have smoked for at least 6 recent months), selected systemic diseases (diabetes, cardiovascular diseases including cardiomyopathy or stroke, hypertension, osteoporosis), cause of tooth loss (dental caries, periodontitis, other), oral health promoting behaviors (average number of dental appointments per year in the recent 5-year period, the most frequent reason to seek dental treatment, frequency of daily tooth brushing, toothbrush replacement intervals, regular cleaning of interdental spaces, dental treatment funding - only in statefinanced facilities, only in private facilities, or mixed way). Weight and height of the subjects were measured to calculate the body mass index (BMI). The following aspects were assessed in a clinical examination: number of teeth (excluding the third molar teeth), number of occlusal supporting zones of natural teeth or fixed prosthetic restorations, plaque on vestibular and lingual surfaces (PI index according to O'Leary et al. was assessed) and also on interdental surfaces (API index according to Lange et al.), bleeding on probing at 4 points around the tooth: distalbuccal, mid-buccal, proximal-buccal and mid-lingual (inflammation extension index, BoP, according to Ainamo and Bay ${ }^{14}$ ), sulcus/pocket depth in 4 analogous points (average PD value for all examined sites and pockets more than $5 \mathrm{~mm}$ ), and clinical attachment level - CAL (number of sites with attachment loss on interproximal surfaces greater than or equal to $3 \mathrm{~mm}$, greater than or equal to $5 \mathrm{~mm}$ and number of gingival recession index greater than or equal to $3 \mathrm{~mm}) .{ }^{12-14}$ Community Periodontal Index (CPI) was assessed based on the result of periodontal examination, and then a periodontal diagnosis was given in line with the recommendations of Centers for Disease Control and the American Academy of Periodontology (CDC/AAP). ${ }^{15-17}$ PEF index and its components were also assessed. Clinical examination of pathological lesions in oral mucosa was conducted (no developmental defects and lesions that do not require treatment were taken into account, e.g., displaced sebaceous glands or varicose veins).

All the investigators (periodontology specialists) were calibrated at the Department of Periodontal and Oral Mucosa Diseases at the Medical University of Warsaw before the project started.

Mean values, medians, ranges ( $\min -\max )$, variances, and standard deviations (SD) of the assessed continuous parameters were calculated for all groups in descriptive statistics. The hypothesis of equality of means in 2 groups was verified with the Mann-Whitney test due to the absence of normal distribution, as verified by the Kolmogorov-Smirnov test with the Lilliefors correction. The hypothesis of equality of means in more than 2 groups was verified with the ANOVA variance analysis, and for groups with non-homogeneous variance with the nonparametric test of Kruskal-Wallis on ranks (variance homogeneity was checked with Levene's test). For parameters that showed statistically significant differences in the comparison of all 3 groups, post-hoc tests were used (Scheffés contrast analysis). For discrete parameters, the frequency of features in groups was analyzed by 
the $\chi^{2} \mathrm{df}$ test (sometimes with the Yates correction) with the corresponding degrees of freedom $\mathrm{df}=(\mathrm{m}-1)(\mathrm{n}-1)$, where $\mathrm{m}=$ number of rows, $\mathrm{n}=$ number of columns. For each test

Table 1. Characteristics of the study population p-value $<0.05$ was considered statistically significant. Statistical analysis was performed with the use of STATISTICA v. 13.1 computer package.

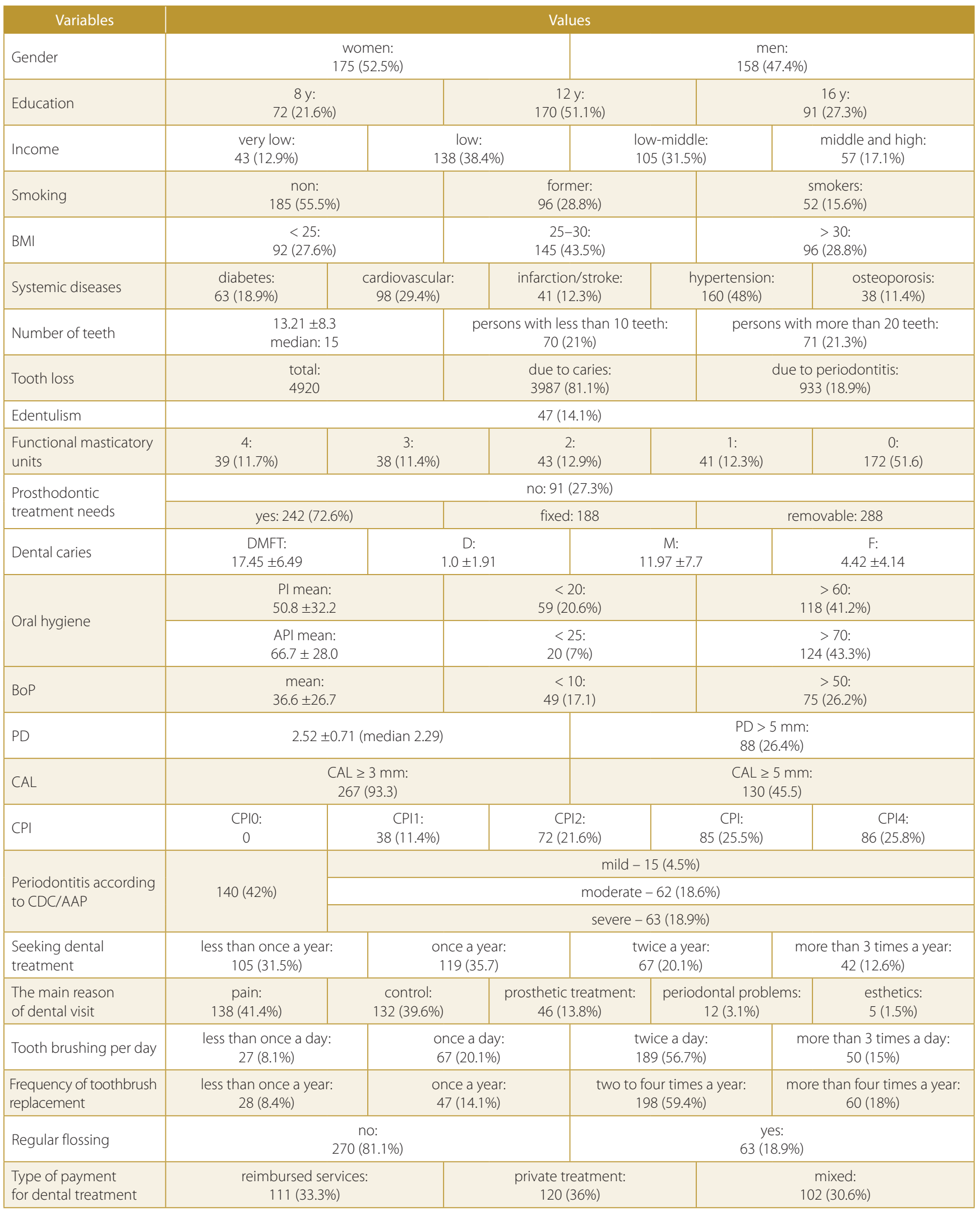

BMI - body mass index; BoP - Bleeding on Probing; PD - Probing Depth; CAL - Clinical Attachement Level; CPI - Community Periodontal Index; CDC/AAP - Center for Disease Control/American Academy of Periodontology. 


\section{Results}

The overall characteristics of the entire study group is shown in Table 1. The average number of the remaining teeth is 13.2 , the proportion of people with edentulism is $14.1 \%$, DMFT amounts up to 17.45 , the percentage of people with periodontitis according to the CDC/AAP is $42 \%$, including $18.9 \%$ with a severe form. Attention is drawn to the relatively low socioeconomic status of the patients, as only $17 \%$ declare income above 2,500 PLN per family member, and as only $27 \%$ of patients declare having a college degree, high prevalence of treated hypertension (almost half of the subjects) and cardiovascular diseases, very high prosthetic needs for more than $70 \%$ of patients, and very poor oral hygiene: only $20 \%$ brush their teeth correctly, and only $7 \%$ clean their interdental spaces (less than 19\% of seniors declare performing this procedure). Less than $1 / 3$ of the subjects have regular

Table 2. Comparison of dental and behavioral parameters between inhabitants of big city (Wrocław) and town (Oława)

\begin{tabular}{|c|c|c|c|c|}
\hline \multicolumn{2}{|c|}{$\begin{array}{c}\text { Dental and behavioral } \\
\text { parameters }\end{array}$} & $\begin{array}{l}\text { Wrocław } \\
(n=256)\end{array}$ & $\begin{array}{l}\text { Oława } \\
(n=77)\end{array}$ & $p$-value \\
\hline \multirow{3}{*}{$\begin{array}{l}\text { Number } \\
\text { of teeth }\end{array}$} & means & $13.98 \pm 8.17$ & $10.63 \pm 8.26$ & 0.001 \\
\hline & $<10(\%)$ & $63(24.6 \%)$ & $8(10.4 \%)$ & 0.007 \\
\hline & $>20(\%)$ & $51(19.9 \%)$ & $19(24.7 \%)$ & 0.001 \\
\hline \multicolumn{2}{|c|}{ Edentulism (\%) } & $30(11.7 \%)$ & $17(22.07 \%)$ & 0.022 \\
\hline \multicolumn{2}{|c|}{$\begin{array}{l}\text { Remaining min. } \\
2 \text { masticatory units (\%) }\end{array}$} & $99(38.7 \%)$ & $21(27.3 \%)$ & 0.06 \\
\hline \multicolumn{2}{|c|}{$\begin{array}{l}\text { Prosthodontic treatment } \\
\text { needs (\%) }\end{array}$} & $184(71.8 \%)$ & $58(75.3 \%)$ & 0.56 \\
\hline \multirow{4}{*}{ Caries } & DMF & $17.05 \pm 6.36$ & $18.8 \pm 6.8$ & 0.029 \\
\hline & D & $1.04 \pm 2.03$ & $0.87 \pm 1.45$ & 0.65 \\
\hline & M & $11.35 \pm 7.48$ & $14.08 \pm 8.1$ & 0.008 \\
\hline & $\mathrm{F}$ & $4.58 \pm 4.2$ & $3.92 \pm 3.94$ & 0.21 \\
\hline \multicolumn{2}{|c|}{ Probing depth means } & $2.55 \pm 0.73$ & $2.42 \pm 0.63$ & 0.15 \\
\hline \multicolumn{2}{|c|}{ Persons with PD > 5 (\%) } & $72(28.1 \%)$ & $16(20.7 \%)$ & 0.19 \\
\hline \multicolumn{2}{|c|}{ Persons with CAL $\geq 3$ (\%) } & $207(80.8 \%)$ & $60(77.9 \%)$ & 0.57 \\
\hline \multicolumn{2}{|l|}{ CPI1 (\%) } & $25(9.8 \%)$ & $13(16.9 \%)$ & 0.08 \\
\hline \multicolumn{2}{|c|}{$\mathrm{CPI3}+\mathrm{CPI}(\%)$} & $134(52.3 \%)$ & $37(48.1 \%)$ & 0.51 \\
\hline \multicolumn{2}{|l|}{ CPI4 (\%) } & $70(27.3 \%)$ & $16(20.7 \%)$ & 0.25 \\
\hline \multicolumn{2}{|c|}{$\begin{array}{l}\text { Periodontitis according to } \\
\text { CDC total (\%) }\end{array}$} & $114(44.5 \%)$ & $26(33.8 \%)$ & 0.09 \\
\hline \multicolumn{2}{|c|}{$\begin{array}{l}\text { Periodontitis according to } \\
\text { CDC severe (\%) }\end{array}$} & $53(20.7 \%)$ & $10(12.9 \%)$ & 0.12 \\
\hline \multicolumn{2}{|l|}{$\mathrm{Pl}$} & $47.6 \pm 31.7$ & $62.9 \pm 31.6$ & 0.001 \\
\hline \multicolumn{2}{|l|}{ API } & $65.2 \pm 28.0$ & $72.7 \pm 27.6$ & 0.051 \\
\hline \multicolumn{2}{|l|}{ BoP } & $36.2 \pm 27.2$ & $38.2 \pm 25.1$ & 0.55 \\
\hline \multicolumn{2}{|c|}{$\begin{array}{l}\text { Regular dental appointments } \\
\text { (at least once a year) (\%) }\end{array}$} & $178(69.5 \%)$ & $50(64.9 \%)$ & 0.45 \\
\hline \multicolumn{2}{|c|}{$\begin{array}{l}\text { Regular brushing (at least } \\
\text { twice a day) (\%) }\end{array}$} & $191(74.6 \%)$ & $48(62.3 \%)$ & 0.0359 \\
\hline \multicolumn{2}{|c|}{ Regular flossing (\%) } & $54(21.1 \%)$ & $9(11.7 \%)$ & 0.06 \\
\hline
\end{tabular}

dental appointments or checkups, and only $1.5 \%$ of the subjects wish to have their dental esthetics improved. For the entire group, 27 clinical diagnoses of pathological lesions in oral mucosa have been made. These are given here in descending order of frequency: denture-related stomatitis and hemangiomas - 21 cases; fibroma - 14; angular cheilitis - 10; scrotal tonque - 9; keratoses - 6; xerostomia and lichen planus - 5; leukoplakia and coated tongue - 4; candidosis, herpes labialis, smoker's palate, geographic tongue, and black hairy tongue - 3; recurrent aphthous stomatitis, Sjögren syndrome, burning mouth syndrome, melanotic macules, naevi, lingua crenata, and papilloma - 2; gingival epulis, halitosis, papillary epithelial hyperplasia, tongue cancer, leukoedema -1 .

The association between the place of residence and dental indicators and oral health behaviors is presented in Table 2. It can be seen that the number of remaining teeth among young seniors in Wrocław is significantly higher

Table 3. Gender stratified dental and behavioral parameters

\begin{tabular}{|c|c|c|c|c|}
\hline \multicolumn{2}{|c|}{$\begin{array}{c}\text { Dental and behavioral } \\
\text { parameters }\end{array}$} & $\begin{array}{l}\text { Wrocław } \\
(n=256)\end{array}$ & $\begin{array}{l}\text { Oława } \\
(n=77)\end{array}$ & $\mathrm{p}$-value \\
\hline \multirow{3}{*}{$\begin{array}{l}\text { Number } \\
\text { of teeth }\end{array}$} & means & $13.65 \pm 8.14$ & $12.81 \pm 8.46$ & 0.32 \\
\hline & $>20(\%)$ & $37(23.4 \%)$ & $34(19.4 \%)$ & 0.37 \\
\hline & $<10(\%)$ & $34(21.5 \%)$ & $36(20.5 \%)$ & 0.83 \\
\hline \multicolumn{2}{|c|}{ Edentulism (\%) } & $18(11.3 \%)$ & $29(16.6 \%)$ & 0.17 \\
\hline \multicolumn{2}{|c|}{$\begin{array}{l}\text { Remaining min. } \\
2 \text { masticatory units (\%) }\end{array}$} & $61(38.6 \%)$ & $59(33.7 \%)$ & 0.35 \\
\hline \multicolumn{2}{|c|}{$\begin{array}{l}\text { Prosthodontic treatment } \\
\text { needs (\%) }\end{array}$} & $122(77.2 \%)$ & $120(68.6 \%)$ & 0.77 \\
\hline \multirow{4}{*}{ Caries } & DMF & $16.81 \pm 6.51$ & $18.04 \pm 6.43$ & 0.15 \\
\hline & D & $1.33 \pm 2.32$ & $0.7 \pm 1.38$ & 0.002 \\
\hline & M & $11.16 \pm 7.41$ & $12.7 \pm 7.88$ & 0.09 \\
\hline & $\mathrm{F}$ & $4.23 \pm 3.84$ & $4.6 \pm 4.4$ & 0.67 \\
\hline \multicolumn{2}{|c|}{ Probing depth means } & $2.62 \pm 0.76$ & $2.42 \pm 0.66$ & 0.008 \\
\hline \multicolumn{2}{|c|}{ Persons with PD > 5 (\%) } & $51(32.2 \%)$ & $37(21.1 \%)$ & 0.021 \\
\hline \multicolumn{2}{|c|}{ Persons with $\mathrm{CAL} \geq 3$ (\%) } & $129(81.6 \%)$ & $138(78.8 \%)$ & 0.52 \\
\hline \multicolumn{2}{|l|}{ CPI1 (\%) } & $12(7.6 \%)$ & $26(14.8 \%)$ & 0.037 \\
\hline \multicolumn{2}{|c|}{$\mathrm{CPI3}+\mathrm{CPI} 4(\%)$} & $88(55.6 \%)$ & $83(47.4 \%)$ & 0.13 \\
\hline \multicolumn{2}{|l|}{ CPI4 (\%) } & $50(31.6 \%)$ & $36(20.6 \%)$ & 0.021 \\
\hline \multicolumn{2}{|c|}{$\begin{array}{l}\text { Periodontitis according to } \\
\text { CDC total (\%) }\end{array}$} & $75(47.5 \%)$ & $65(37.1 \%)$ & 0.056 \\
\hline \multicolumn{2}{|c|}{$\begin{array}{l}\text { Periodontitis according to } \\
\text { CDC severe (\%) }\end{array}$} & $36(22.7 \%)$ & $27(15.4 \%)$ & 0.087 \\
\hline \multicolumn{2}{|l|}{ PI } & $60.18 \pm 31.35$ & $41.81 \pm 30.51$ & 0.0000 \\
\hline \multicolumn{2}{|l|}{ API } & $75.77 \pm 25.15$ & $58.15 \pm 28.01$ & 0.0000 \\
\hline \multicolumn{2}{|l|}{ BoP } & $42.27 \pm 28.08$ & $31.21 \pm 24.36$ & 0.0005 \\
\hline \multicolumn{2}{|c|}{$\begin{array}{l}\text { Regular dental appointments } \\
\text { (at least once a year) (\%) }\end{array}$} & 105 (66.4\%) & $123(70.3 \%)$ & 0.45 \\
\hline \multicolumn{2}{|c|}{$\begin{array}{l}\text { Regular brushing (at least } \\
\text { twice a day) (\%) }\end{array}$} & 99 (62.6\%) & $140(80 \%)$ & 0.0004 \\
\hline \multicolumn{2}{|c|}{ Regular flossing (\%) } & $13(8.2 \%)$ & $50(28.6 \%)$ & 0.0000 \\
\hline
\end{tabular}

DMF - Decay, Missing, Filling; PD - Probing Depth; CAL - Clinical Attachement Level; CPI - Community Periodontal Index; CDC - Center for Disease Control; $\mathrm{PI}$ - Plaque Index; API - Approximal Plaque-Index; BoP - Bleeding on Probing. 
due to the greater frequency of tooth removal caused by caries in smaller towns. This probably leads to a greater prevalence of edentulism in this age group, although the difference in severe tooth loss $(<10)$ is not significant. The indicators of periodontitis do not differ significantly between residents of these 2 urban environments. Younger seniors from a large city are more likely to brush their teeth regularly, which contributes to less plaque on the vestibular and lingual surfaces. As far as flossing and cleaning of interdental spaces are concerned, the trend is similar, although it is not at the level of statistical significance. The most common pathologies of oral mucous membrane found among the inhabitants of Wrocław are: denture-related stomatitis - 17 cases, haemangiomas -16 , fibroma -12 ; among the inhabitants of Oława: hemangiomas -5 cases, denture-related stomatitis, angular cheilitis, and xerostomia -4 cases. A recurrence of tongue cancer (following removal) has been diagnosed in a 66-year-old female resident of Oława.

The influence of gender has been particularly visible in oral health promoting behaviors (Table 3). Regular brushing and flossing have been found considerably more frequently among women, which is probably the main reason for the remarkably better oral hygiene and less extensive gingivitis than in men. On the other hand, among men the incidence of dental caries was significantly higher $(p=0.002)$, along with periodontal indicators (deeper periodontal pockets, higher percentage of subjects with pockets deeper than $5 \mathrm{~mm}$ and higher percentage of subject with CPI4). Sexual dimorphism related to clinical dental parameters did not translate into differences in the number of teeth and incidence of edentulism.

The control group for the occurrence of systemic diseases comprised of subjects who did not have the history of a systemic disease affecting oral health, in the light of current medical knowledge, or were not treated for a long time (80 people). No statistical relationship between diabetes and cardiovascular diseases and the analyzed dental indicators and oral hygiene behavior descriptors has been shown (Table 4). Considerably more frequent extractions of periodontal teeth and a lower DMFT index were found in patients with previous myo-

Table 4. Association of dental and behavioral parameters with systemic diseases

\begin{tabular}{|c|c|c|c|c|c|c|c|}
\hline \multicolumn{2}{|c|}{ Dental and behavioral parameters } & $\begin{array}{l}\text { Diabetes } \\
(n=63)\end{array}$ & $\begin{array}{l}\text { Cardiovascular } \\
\text { disease }(n=96)\end{array}$ & $\begin{array}{c}\text { Infarction/ } \\
\text { stroke }(n=41)\end{array}$ & $\begin{array}{l}\text { Osteoporosis } \\
(n=38)\end{array}$ & $\begin{array}{l}\text { Hypertension } \\
(\mathrm{n}=78)\end{array}$ & $\begin{array}{l}\text { Control } \\
(\mathrm{n}=80)\end{array}$ \\
\hline \multirow{3}{*}{ Number of teeth } & means & $11.8 \pm 8.0$ & $12.2 \pm 8.4$ & $11.7 \pm 8.8$ & $14.6 \pm 8.6$ & $14.4 \pm 8.2$ & $12.8 \pm 8.1$ \\
\hline & $>20(\%)$ & $9(15.0 \%)$ & $18(18.7 \%)$ & $6(14.6 \%)$ & $12(31.5 \%)$ & $16(20.5 \%)$ & $15(18.7 \%)$ \\
\hline & $<10(\%)$ & $10(15.8 \%)$ & $19(19.9 \%)$ & $5(12.2 \%)$ & $7(18.4 \%)$ & $14(17.9 \%)$ & $21(26.2 \%)$ \\
\hline \multicolumn{2}{|l|}{ Edentulism (\%) } & $10(15.8 \%)$ & $18(18.7 \%)$ & $10(24.4 \%)$ & $4(10.5 \%)$ & $9(11.5 \%)$ & $11(13.7 \%)$ \\
\hline \multirow{4}{*}{ Caries } & DMF & $17.2 \pm 6.4$ & $16.4 \pm 7.41$ & $14.6 \pm 7.3^{\mathrm{a}}$ & $18.0 \pm 6.1$ & $17.7 \pm 6.5$ & $17.8 \pm 6.6$ \\
\hline & $\mathrm{D}$ & $0.97 \pm 1.6$ & $0.96 \pm 1.0$ & $1.09 \pm 2.2$ & $0.84 \pm 1.5$ & $0.8 \pm 1.4$ & $1.35 \pm 2.5$ \\
\hline & M & $12.4 \pm 7.3$ & $11.6 \pm 8.0$ & $9.97 \pm 7.5$ & $11.9 \pm 8.3$ & $11.9 \pm 8.0$ & $12.1 \pm 7.4$ \\
\hline & $\mathrm{F}$ & $3.6 \pm 3.9$ & $3.7 \pm 3.8$ & $3.6 \pm 3.5$ & $5.2 \pm 4.9$ & $5.0 \pm 4.1$ & $4.3 \pm 3.9$ \\
\hline \multirow[b]{2}{*}{ PD } & means & $2.48 \pm 0.58$ & $2.59 \pm 0.73$ & $2.62 \pm 0.8$ & $2.5 \pm 0.7$ & $2.44 \pm 0.6$ & $2.62 \pm 0.88$ \\
\hline & $\begin{array}{l}\text { persons with } \\
\mathrm{PD}>5 \mathrm{OR} 95 \% \mathrm{Cl}\end{array}$ & $1.15(0.9-1.4)$ & $1.0(0.8-1.07)$ & $1.07(0.9-1.3)$ & $0.92(0.8-1.1)$ & $1.07(0.9-1.3)$ & Ref. \\
\hline \multicolumn{2}{|c|}{ Persons with $\mathrm{CAL} \geq 3 \mathrm{OR}$} & $0.96(0.8-1.1)$ & $0.93(0.9-1.0)$ & $0.95(0.8-1.1)$ & $1.02(0.9-1.1)$ & $1.05(0.9-1.1)$ & Ref. \\
\hline \multicolumn{2}{|c|}{ Periodontitis as cause of tooth loss } & $3.69 \pm 6.9$ & $4.2 \pm 7.4$ & $6.27 \pm 9.2^{b}$ & $1.42 \pm 4.1$ & $1.59 \pm 5.3^{c}$ & $3.0 \pm 4.7$ \\
\hline \multirow{3}{*}{ CPI } & CPI0 OR 95\% Cl & $0.96(0.6-1.5)$ & $0.76(0.5-1.2)$ & $0.79(0.4-1.5)$ & $0.99(0.5-1.3)$ & $1.35(0.8-2.3)$ & Ref. \\
\hline & CPI3 OR 95\% Cl & $1.08(0.8-1.5)$ & $0.99(0.7-1.4)$ & $1.13(0.7-1.9)$ & $0.97(0.6-1.6)$ & $1.29(0.9-1.9)$ & Ref. \\
\hline & CPI4 OR 95\% Cl & $0.88(0.6-1.2)$ & $1.06(0.6-1.8)$ & $0.83(0.4-1.6)$ & $1.01(0.5-2.2)$ & $0.93(0.5-1.7)$ & Ref. \\
\hline \multicolumn{2}{|c|}{$\begin{array}{l}\text { Periodontitis according to CDC/AAP } \\
\text { Severe OR } 95 \% \mathrm{Cl}\end{array}$} & $1.17(0.3-4.5)$ & $2.19(0.7-6.8)$ & $2.48(0.5-11.4)$ & $1.14(0.3-4.3)$ & $0.18(0.04-0.76)$ & Ref. \\
\hline \multirow{2}{*}{ Oral hygiene } & $\mathrm{Pl}$ & $56.8 \pm 32.0$ & $50.2 \pm 32.3$ & $48.4 \pm 32.4$ & $40.7 \pm 29.7$ & $51.9 \pm 29.8$ & $52.4 \pm 33.2$ \\
\hline & API & $67.2 \pm 27.9$ & $70.5 \pm 27.3$ & $68.7 \pm 29.3$ & $54.7 \pm 28.8^{d}$ & $65.7 \pm 25.8$ & $68.3 \pm 27.2$ \\
\hline \multicolumn{2}{|l|}{ BoP } & $38.7 \pm 29.3$ & $39.7 \pm 27.5$ & $42.0 .7 \pm 28.6$ & $40.4 \pm 28.1$ & $33.7 \pm 24.9$ & $38.3 \pm 29.2$ \\
\hline \multicolumn{2}{|c|}{$\begin{array}{l}\text { Regular dental appointments } \\
\text { (at least once a year) OR }\end{array}$} & $1.16(0.8-1.6)$ & $1.25(0.9-1.7)$ & $1.14(0.7-1.8)$ & $1.22(0.8-1.8)$ & $0.87(0.6-1.2)$ & Ref. \\
\hline \multicolumn{2}{|c|}{$\begin{array}{l}\text { Regular brushing } \\
\text { (at least twice a day) OR }\end{array}$} & $0.88(0.6-1.4)$ & $1.05(0.9-1.7)$ & $1.1(0.7-1.8)$ & $0.8(0.5-1.3)$ & $1.25(0.8-1.9)$ & Ref. \\
\hline \multicolumn{2}{|c|}{ Regular flossing OR } & $1.29(0.5-3.3)$ & $2.01(0.8-5.1)$ & $2.44(0.6-9.5)$ & $0.3(0.1-0.84)$ & $0.42(0.2-1.1)$ & Ref. \\
\hline
\end{tabular}

DMF - Decay, Missing, Filling; PD - Probing Depth; CI - Confidence Interval; CAL - Clinical Attachement Level; OR - Odds Ratio; CPI - Community Periodontal Index; CDC/AAP - Center for Disease Control/American Academy of Periodontology; PI - Plaque Index; API - Approximal Plaque-Index; BoP - Bleeding on Probing. ${ }^{a} p=0.027 ;{ }^{b} p=0.049 ;{ }^{c} p=0.026 ;{ }^{d} p=0.013$. 
cardial infarction or stroke. Osteoporosis patients showed significantly better hygiene in interdental spaces as a result of significantly more frequent regular cleansing, possibly related to female gender. Furthermore, patients with hypertension underwent a lower number of periodontal teeth removals, and they rarely had severe periodontal disease according to CDC/AAP.

The analysis of the relationship between smoking and body weight and clinical dental exponents and selected oral health related behaviors of the examined subjects is presented in Table 5. No significant relationship was found between body mass stratification in line with BMI and dental and behavioral parameters. Still, there has been shown a significant negative impact of current tobacco dependence on the reduction of the number of teeth and the presence of more than 20 teeth (functional dentition), dental caries exponents (higher number of cavities and a lower number of fillings), periodontal parameters (higher mean pocket depth and the percentage of subjects with pockets deeper than $5 \mathrm{~mm}$, more frequent occurrence of $3 \mathrm{~mm} C A L$, more frequent occurrence of severe periodontitis according to CDC/AAP and CPI4 Code, and less frequent occurrence of CPIO Code), and oral hygiene (higher mean PI and API scores). Current nicotine addicts also showed significantly worse oral health attitudes by comparison to non-smokers (less frequent regular tooth brushing and interdental spaces cleaning). Also, in the former nicotine addicts, there was a persistence of significantly worse clinical indicators related to oral health compared to those of non-smokers: significantly lower (by almost 3 teeth) average number of teeth, higher number of subject with severe tooth loss $(<10)$ and lower number of subjects with remaining functional dentition (> 20) and lower number of fillings. Current smokers, by comparison with the former ones, had significantly more dental caries defects as well as a higher mean PD.

Table 5. Association of dental and behavioral parameters with smoking and body mass index

\begin{tabular}{|c|c|c|c|c|c|c|c|}
\hline \multirow{2}{*}{\multicolumn{2}{|c|}{ Dental and behavioral parameters }} & \multicolumn{3}{|c|}{ Smoking } & \multicolumn{3}{|c|}{ BMI } \\
\hline & & \multirow{2}{*}{$\begin{array}{l}\text { current } \\
(n=52) \\
11.8 \pm 8.01\end{array}$} & \multirow{2}{*}{$\begin{array}{c}\text { past } \\
(n=96) \\
11.6 \pm 7.8^{a}\end{array}$} & \multirow{2}{*}{$\begin{array}{c}\text { never } \\
(n=185) \\
14.4 \pm 8.5\end{array}$} & \multirow{2}{*}{$\begin{array}{c}\text { obese } \\
(\mathrm{n}=96) \\
12.5 \pm 8.7\end{array}$} & \multirow{2}{*}{$\begin{array}{l}\text { overweight } \\
(n=145) \\
14.0 \pm 7.5\end{array}$} & \multirow{2}{*}{$\begin{array}{l}\text { normal } \\
(n=92) \\
12.7 \pm 9.0\end{array}$} \\
\hline \multirow{3}{*}{ number of teeth } & means & & & & & & \\
\hline & $>20(\%)$ & $6(11.5 \%)^{b}$ & $14(14.6 \%)^{c}$ & $51(27,6 \%)$ & $18(18.7 \%)$ & $29(20 \%)$ & $24(26 \%)$ \\
\hline & $<10(\%)$ & $10(19.2 \%)$ & $27(28.1 \%)^{d}$ & $33(17.8 \%)$ & $20(20.8 \%)$ & $33(22.7 \%)$ & $17(18.5 \%)$ \\
\hline \multicolumn{2}{|l|}{ Edentulism (\%) } & $10(19.2 \%)$ & $13(13.5 \%)$ & $24(12.9 \%)$ & $17(17.7 \%)$ & $12(8.3 \%)$ & 18(19.6\%) \\
\hline \multirow{4}{*}{ Caries } & DMF & $17.5 \pm 7.4$ & $18.3 \pm 6.6$ & $17.0 \pm 6.3$ & $17.6 \pm 6.9$ & $17.2 \pm 6.2$ & $17.7 \pm 6.6$ \\
\hline & $D$ & $1.88 \pm 2.6^{\mathrm{ef}}$ & $1.08 \pm 2.3$ & $0.71 \pm 1.3$ & $0.89 \pm 1.5$ & $1.16 \pm 1.9$ & $0.85 \pm 2.2$ \\
\hline & M & $12.4 \pm 8.3$ & $13.4 \pm 7.4$ & $11.1 \pm 7.6$ & $12.5 \pm 8.0$ & $11.5 \pm 7.2$ & $12.3 \pm 8.1$ \\
\hline & $\mathrm{F}$ & $3.25 \pm 3.2^{9}$ & $3.7 \pm 3.7^{h}$ & $5.1 \pm 4.6$ & $4.1 \pm 4.4$ & $4.6 \pm 3.8$ & $4.5 \pm 4.4$ \\
\hline \multirow[b]{2}{*}{ PD } & means & $2.94 \pm 0.89^{i j}$ & $2.56 \pm 0.71$ & $2.39 \pm 0.61$ & $2.54 \pm 0.63$ & $2.49 \pm 0.7$ & $2.55 \pm 0.81$ \\
\hline & $\begin{array}{c}\text { persons with } \\
\text { PD }>5 \text { OR } 95 \% \mathrm{Cl}\end{array}$ & $177.5^{k}$ & 145.4 & 133.6 & 143.5 & 142.1 & 145.9 \\
\hline \multicolumn{2}{|c|}{ Persons with $C A L \geq 3$ OR } & $173.8^{\prime}$ & 149.1 & 132.7 & 145.1 & 143.0 & 142.6 \\
\hline \multicolumn{2}{|c|}{ Periodontitis as cause of tooth loss } & $3.84 \pm 7.5$ & $2.95 \pm 6.3$ & $2.42 \pm 5.9$ & $3.04 \pm 4.8$ & $2.51 \pm 5.9$ & $3.01 \pm 6.4$ \\
\hline \multirow{3}{*}{ CPI } & CPI0 OR 95\% Cl & $102.2^{m}$ & 132.5 & 156.4 & 143.4 & 138.4 & 145.0 \\
\hline & CPI3 OR 95\% Cl & 165.2 & 136.5 & 137.7 & 144.1 & 143.5 & 135.2 \\
\hline & CPI4 OR 95\% Cl & $177.5^{n}$ & 141.0 & 132.7 & 139.2 & 142.0 & 143.1 \\
\hline \multicolumn{2}{|c|}{$\begin{array}{l}\text { Periodontitis according to CDC/AAP } \\
\text { Severe OR } 95 \% \mathrm{Cl}\end{array}$} & $166.5^{\circ}$ & 148.2 & 135.1 & 144.6 & 142.1 & 144.9 \\
\hline \multirow{2}{*}{ Oral hygiene } & $\mathrm{PI}$ & $65.7 \pm 32.4^{p}$ & $54.4 \pm 32.8$ & $45.0 \pm 30.5$ & $57.3 \pm 32.7$ & $48.2 \pm 31.4$ & $48.5 \pm 32.6$ \\
\hline & API & $79.2 \pm 26.0^{r}$ & $66.9 \pm 29.7$ & $63.5 \pm 26.9$ & $70.0 \pm 28.7$ & $65.3 \pm 28.6$ & $66.0 \pm 26.5$ \\
\hline \multicolumn{2}{|l|}{ BoP } & $43.7 \pm 27.8$ & $38.1 \pm 26.4$ & $34.0 \pm 26.5$ & $39.9 \pm 29.4$ & $36.3 \pm 24.4$ & $33.7 \pm 28.0$ \\
\hline \multicolumn{2}{|c|}{$\begin{array}{l}\text { Regular dental appointments } \\
\text { (at least once a year) OR }\end{array}$} & 155.9 & 155.5 & 176.1 & 158.2 & 173.1 & 166.6 \\
\hline \multicolumn{2}{|c|}{$\begin{array}{l}\text { Regular brushing } \\
\text { (at least twice a day) OR }\end{array}$} & 140.0 & 160.2 & $178.1^{\mathrm{s}}$ & 164.9 & 163.6 & 174.6 \\
\hline \multicolumn{2}{|c|}{ Regular flossing OR } & 154.7 & 158.0 & $175.1^{\mathrm{t}}$ & 163.3 & 164.2 & 175.3 \\
\hline
\end{tabular}

DMF - Decay, Missing, Filling; PD - Probing Depth; Cl - Confidence Interval; CAL - Clinical Attachement Level; OR - Odds Ratio; CPI - Community Periodontal Index; CDC/AAP - Center for Disease Control/American Academy of Periodontology; PI - Plaque Index; API - Approximal Plaque-Index; BoP - Bleeding on Probing. ${ }^{a} p=0.0022$ vs never; ${ }^{b} p=0.0171$ vs never $;{ }^{c} p=0.014$ vs never; ${ }^{d} p=0.046$ vs never; ${ }^{e} p=0.0004$ vs never; ${ }^{f} p=0.046$ vs past; ${ }^{9} p=0.014$ vs never; ${ }^{\mathrm{h}} p=0.022$ vs never; ${ }^{i} p=0.0000$ vs never; ${ }^{j} p=0.015$ vs past; ${ }^{k} p=0.0008$ vs never; ${ }^{l} p=0.0056$ vs never; ${ }^{m} p=0.0002$ vs never; ${ }^{n} p=0.001$ vs never; ${ }^{\circ} p=0.0066$ vs never; ${ }^{p} p=0.0008$ vs never; ${ }^{r} p=0.005$ vs never; ${ }^{s} p=0.012$ vs current; ${ }^{t} p=0.039$ vs current. 
Table 6 contains the results of an analysis showing the crucial influence of social and economic factors (education, income and dental treatment type - public/ private) on the number of teeth. All 3 factors had a significant influence on the average number of remaining teeth, the presence of more than 20 teeth, the proportion of edentulism, and the number of teeth removed for cariological and periodontal reasons. In each case, these indicators are by far the worst in subjects treated only in public health care facilities, with the lowest income per family member, and with primary education only. Socioeconomic factors did not significantly affect caries (the number of D and DMFT, except for the one significantly lower in patients treated privately, but this was due to caries-related extraction) and periodontal disease
(PD, CAL, CPI codes and diagnosis of periodontitis according to CDC/AAP). It has also been found that these determinants have a significant influence on health promoting behaviors. The higher the income, education and self-paid dental treatment, the better the standard of oral hygiene, the smaller the extent of gingivitis, the more frequent dental treatment, and the more frequent brushing and cleaning of interdental spaces.

\section{Discussion}

Only 3 Polish cross-sectional studies on oral health of persons aged 65 to 74 years have been found in the available medical literature from the last decade. ${ }^{18-20}$ The sam-

Table 6. Association between socioeconomic factors/type of dental service and dental/ behavioral parameters

\begin{tabular}{|c|c|c|c|c|c|c|c|c|c|}
\hline \multirow{2}{*}{\multicolumn{2}{|c|}{ Dental and behavioral parameters }} & \multicolumn{3}{|c|}{ Education } & \multicolumn{3}{|c|}{ Income } & \multicolumn{2}{|c|}{ Dental service } \\
\hline & & \multirow{2}{*}{$\begin{array}{c}8 y: \\
(n=72) \\
9.94 \pm 8.4\end{array}$} & \multirow{2}{*}{$\begin{array}{c}12 \mathrm{y}: \\
(\mathrm{n}=170) \\
12.5 \pm 8.1\end{array}$} & \multirow{2}{*}{$\begin{array}{c}\min .16 y: \\
(n=91) \\
17.08 \pm 7.1^{a b}\end{array}$} & \multirow{2}{*}{$\begin{array}{l}\text { Lowest: } \\
(\mathrm{n}=43) \\
7.93 \pm 7.9\end{array}$} & \multirow{2}{*}{$\begin{array}{l}\text { Medium: } \\
(\mathrm{n}=233) \\
14.6 \pm 7.8^{\mathrm{a}}\end{array}$} & \multirow{2}{*}{$\begin{array}{c}\text { High: } \\
(\mathrm{n}=57) \\
17.7 \pm 6.9^{\mathrm{bc}}\end{array}$} & \multirow{2}{*}{$\begin{array}{l}\text { Reimb.: } \\
(n=111) \\
8.26 \pm 7.9\end{array}$} & \multirow{2}{*}{$\begin{array}{l}\text { Private: } \\
(\mathrm{n}=120) \\
17.37 \pm 7.2\end{array}$} \\
\hline \multirow{3}{*}{ Number of teeth } & means & & & & & & & & \\
\hline & $>20(\%)$ & $9(12.5 \%)$ & $30(17.6 \%)$ & $32(35,1 \%)^{c d}$ & $3(6.9 \%)$ & $45(19.3 \%)$ & 23 (40.3\%de & $9(8.1 \%)$ & $47\left(39.2 \%{ }^{b}\right.$ \\
\hline & $<10(\%)$ & $18(25 \%)$ & $40(23.5 \%)$ & $12(13.1 \%)$ & $11(25.6 \%)$ & $52(22.3 \%)$ & $7(12.2 \%)$ & $31\left(27.9 \%^{c}\right.$ & $17(14.2 \%)$ \\
\hline \multirow{4}{*}{ Caries } & DMF & $18.1 \pm 7.6$ & $17.7 \pm 6.5$ & $16.46 \pm 5.4$ & $17.7 \pm 8.3$ & $17.2 \pm 5.6$ & $16.12 \pm 5.9$ & $18.8 \pm 8.1^{e}$ & $16.4 \pm 5.5$ \\
\hline & D & $1.23 \pm 2.0$ & $0.87 \pm 2.0$ & $1.07 \pm 1.6$ & $1.44 \pm 3.4$ & $0.87 \pm 1.5$ & $0.85 \pm 1.6$ & $1.28 \pm 2.3$ & $0.88 \pm 1.6$ \\
\hline & M & $13.9 \pm 8.8^{9}$ & $12.4 \pm 7.6^{h}$ & $9.6 \pm 6.3$ & $14.1 \pm 9.1^{i}$ & $11.3 \pm 6.9$ & $9.2 \pm 6.7$ & $15.1 \pm 8.7^{f}$ & $9.4 \pm 6.7$ \\
\hline & $\mathrm{F}$ & $2.97 \pm 3.7$ & $4.4 \pm 4.2^{i}$ & $5.6 \pm 3.9^{j}$ & $2.18 \pm 3.0$ & $4.96 \pm 4.2^{j}$ & $5.92 \pm 3.9^{k}$ & $2.36 \pm 3.3$ & $6.01 \pm 4.5^{9}$ \\
\hline PD & means & $2.55 \pm 0.7$ & $2.5 \pm 0.7$ & $2.55 \pm 0.76$ & $2.74 \pm 0.94$ & $2.46 \pm 0.63$ & $2.61 \pm 0.88$ & $2.55 \pm 0.75$ & $2.54 \pm 0.78$ \\
\hline \multicolumn{2}{|c|}{ Persons with $\mathrm{CAL} \geq 3 \mathrm{OR}$} & 143.5 & 140.1 & 149.2 & 94.2 & 86.8 & 96.6 & 137.8 & 149.3 \\
\hline \multicolumn{2}{|c|}{ Periodontitis as cause of tooth loss } & $4.14 \pm 7.72^{k}$ & $3.05 \pm 6.52$ & $1.28 \pm 3.9$ & $5.93 \pm 9.1^{1}$ & $2.1 \pm 4.9$ & $0.98 \pm 4.1$ & $4.62 \pm 8.1^{h}$ & $1.2 \pm 4.1$ \\
\hline \multirow{3}{*}{ CPI } & CPI0 OR 95\% Cl & 129.2 & 140.6 & 150.6 & 79.4 & 90.6 & 92.5 & 127.6 & $152.7^{i}$ \\
\hline & CPI3 OR 95\% Cl & 135.8 & 137.6 & 151.5 & 85.4 & 84.4 & 100.4 & 129.3 & 144.5 \\
\hline & CPI4 OR 95\% Cl & 142.6 & 137.5 & 147.4 & 93.6 & 85.1 & 95.3 & 131.7 & 149.9 \\
\hline \multicolumn{2}{|c|}{$\begin{array}{l}\text { Periodontitis according to CDC/AAP } \\
\text { Severe OR } 95 \% \mathrm{Cl}\end{array}$} & 149.1 & 143.6 & 139.9 & 100.1 & 90.6 & 87.2 & 144.0 & 141.8 \\
\hline \multirow{2}{*}{ Oral hygiene } & $\mathrm{PI}$ & $59.7 \pm 32.4^{1}$ & $51.5 \pm 32.2$ & $44.0 \pm 30.9$ & $69.1 \pm 26.5^{\mathrm{mn}}$ & $46.2 \pm 31.8$ & $44.3 \pm 31.2$ & $62.1 \pm 34.0^{j}$ & $46.8 \pm 28.8$ \\
\hline & API & $72.5 \pm 29.4$ & $66.5 \pm 27.9$ & $63.6 \pm 27.0$ & $81.5 \pm 20.4^{\mathrm{op}}$ & $63.7 \pm 29.3$ & $62.7 \pm 22.7$ & $75.3 \pm 27.2^{k}$ & $60.9 \pm 26.1$ \\
\hline \multicolumn{2}{|l|}{ BoP } & $48.6 \pm 30.4^{m n}$ & $34.6 \pm 25.4$ & $32.5 \pm 24.7$ & $54.0 \pm 33.0^{\text {rs }}$ & $34.6 \pm 25.0$ & $31.6 \pm 24.5$ & $44.4 \pm 30.0^{\prime}$ & $33.7 \pm 27.3$ \\
\hline \multicolumn{2}{|c|}{$\begin{array}{l}\text { Regular dental appointments } \\
\text { (at least once a year) OR }\end{array}$} & 124.8 & $171.7^{\circ}$ & $191.5^{p}$ & 72.8 & 106.6 & $119.2^{\mathrm{t}}$ & 119.6 & $202.0^{\mathrm{m}}$ \\
\hline \multicolumn{2}{|c|}{$\begin{array}{l}\text { Regular brushing } \\
\text { (at least twice a day) OR }\end{array}$} & 126.3 & $173.5^{r}$ & $187.1^{\mathrm{s}}$ & 81.5 & 106.5 & $112.9^{u}$ & 131.3 & $191.3^{n}$ \\
\hline \multicolumn{2}{|c|}{ Regular flossing OR } & 142.4 & 166.8 & $186.7^{\mathrm{t}}$ & 83.8 & 106.8 & $110.3^{w}$ & 143.0 & $184.1^{\circ}$ \\
\hline
\end{tabular}

DMF - Decay, Missing, Filling; PD - Probing Depth; Cl - Confidence Interval; CAL - Clinical Attachement Level; OR - Odds Ratio; CPI - Community Periodontal Index; CDC/AAP - Center for Disease Control/American Academy of Periodontology; PI - Plaque Index; API - Approximal Plaque-Index; BoP - Bleeding on Probing ${ }^{a} p=0.0000$ vs $8 y ;{ }^{b} p=0.0000$ vs $12 y ;{ }^{c} p=0.001$ vs $8 y ;{ }^{d} p=0.001$ vs $12 y ;{ }^{e} p=0.0003$ vs $16 y ;{ }^{f} p=0.02$ vs $16 y ;{ }^{9} p=0.001$ vs $16 y ;{ }^{h} p=0.0017$ vs $16 y ;$ ${ }^{i} p=0.045$ vs $8 y ;{ }^{j} p=0.0002$ vs $8 y ;{ }^{k} p=0.0156$ vs $16 y ;{ }^{i} p=0.018$ vs $16 y ;{ }^{m} p=0.002$ vs $8 y ;{ }^{n} p=0.004$ vs $12 y ;{ }^{\circ} p=0.002$ vs $8 y ;{ }^{p} p=0.0000$ vs $8 y ;$

${ }^{r} p=0.003$ vs $8 y ;{ }^{s} p=0.0000$ vs $8 y ;{ }^{t} p=0.0018 y ;$

${ }^{\mathrm{a}} \mathrm{p}=0.0000$ vs lowest; ${ }^{\mathrm{b}} \mathrm{p}=0.0000$ vs lowest; ${ }^{\mathrm{c}} \mathrm{p}=0.045$ vs medium; ${ }^{\mathrm{d}} \mathrm{p}=0.0004$ vs lowest; ${ }^{\mathrm{e}} \mathrm{p}=0.0008$ vs medium; ${ }^{\mathrm{f}} \mathrm{p}=0.0000$ vs high; ${ }^{9} \mathrm{p}=0.0005$ vs medium;

${ }^{\mathrm{h}} \mathrm{p}=0.024$ vs high; $\mathrm{i}=0.005$ vs high; $\mathrm{j} p=0.0006$ vs lowest; ${ }^{k} p=0.0000$ vs lowest; $\mathrm{p}=0003$ vs medium high; $\mathrm{m} p=0.003$ vs high; ${ }^{\mathrm{n}} \mathrm{p}=0.0031$ vs medium;

${ }^{\circ} p=0.015$ vs high; ${ }^{p} p=0.012$ vs medium; $p=0.0013$ vs high; ${ }^{\mathrm{s}} p=0.0032$ vs medium; ${ }^{\mathrm{t}} p=0.002$ vs lowest; ${ }^{\mathrm{u}} p=0.01$ vs lowest; ${ }^{\mathrm{w}} p=0.003$ vs lowest;

${ }^{a} p=0.0000 ;{ }^{b} p=0.0000 ;{ }^{c} p=0.01 ;{ }^{d} p=0.0000 ;{ }^{e} p=0.009 ;{ }^{f} p=0.0000 ;{ }^{g} p=0.0000 ;{ }^{h} p=0.0002 ;{ }^{i} p=0.023 ;{ }^{j} p=0.0001 ;{ }^{k} p=0.0001 ;{ }^{l} p=0.0082 ;$

${ }^{m} p=0.0000 ;{ }^{n} p=0.0000 ;{ }^{\circ} p=0.0000$ 
Table 7. Comparison of selected regional cross-sectional studies conducted in young seniors

\begin{tabular}{|c|c|c|c|c|c|c|}
\hline \multicolumn{3}{|c|}{$\begin{array}{c}\text { Dental and behavioral } \\
\text { parameters }\end{array}$} & $\begin{array}{l}\text { INVEST }^{21,22} \\
\text { (Whites 133) }\end{array}$ & $\begin{array}{l}\text { SHIP } 22,23 \\
(n=554)\end{array}$ & $\begin{array}{l}\text { Turin }{ }^{24} \\
(n=191)\end{array}$ & $\begin{array}{l}\text { Wrocław } \\
(n=333)\end{array}$ \\
\hline \multicolumn{3}{|c|}{ Age (means or intervals) } & $70.8 \pm 6.9$ & $65-74$ & $60-75$ & $69.53 \pm 2.74$ \\
\hline \multicolumn{3}{|c|}{ Female (\%) } & 57.4 & $50 \%$ & 52.3 & 52.5 \\
\hline \multicolumn{3}{|c|}{ Number of teeth (means) } & 19.0 & $10.6 a$ & 20.62 & $13.21 \pm 8.3$ \\
\hline \multicolumn{3}{|c|}{ Edentulism (\%) } & 10.1 & 15.8 & 1 & 14.1 \\
\hline \multirow{2}{*}{\multicolumn{2}{|c|}{$\begin{array}{l}\text { Probing depth } \\
\text { persons with } \\
\text { PD }>5\end{array}$}} & means & 2.2 & $2.8 a$ & ND & $2.52 \pm 0.71$ \\
\hline & & (\%) & 30.1 & 28.1 & ND & 26.4 \\
\hline \multirow{2}{*}{ CAL } & \multicolumn{2}{|c|}{$\begin{array}{l}\text { persons with } \\
C A L \geq 3(\%)\end{array}$} & ND & 99.4 & ND & 93.3 \\
\hline & \multicolumn{2}{|c|}{$\begin{array}{l}\text { persons with } \\
C A L \geq 5(\%)\end{array}$} & 63.0 & 80.2 & ND & 45.5 \\
\hline \multirow{2}{*}{\multicolumn{2}{|c|}{$\begin{array}{l}\text { Periodontitis } \\
\text { acc. to } \\
\text { CDC/AAP }\end{array}$}} & $\begin{array}{l}\text { moderate } \\
(\%)\end{array}$ & 43.7 & 52.3 & 36.1 & 18.6 \\
\hline & & $\begin{array}{l}\text { severe } \\
(\%)\end{array}$ & 14.3 & 30.0 & 51.3 & 18,9 \\
\hline \multicolumn{3}{|c|}{ Current smokers (\%) } & 7.4 & $13.7^{\mathrm{a}}$ & 23.5 & 15,6 \\
\hline \multicolumn{3}{|c|}{ Obesity acc. BMI (\%) } & 30.25 & $33.1^{\mathrm{a}}$ & ND & 28.8 \\
\hline \multicolumn{3}{|c|}{ Diabetes (\%) } & 13.9 & $18.2^{\mathrm{a}}$ & 5.8 & 18.9 \\
\hline \multicolumn{3}{|l|}{ BoP } & 22.1 & $43.3^{a}$ & ND & $36.6 \pm 26.7$ \\
\hline \multicolumn{3}{|c|}{$\begin{array}{l}\text { Regular brushing } \\
\text { (at least twice a day) (\%) }\end{array}$} & 73.2 & $78.8^{\mathrm{a}}$ & ND & 71.7 \\
\hline \multicolumn{3}{|c|}{ Regular flossing (\%) } & 55.6 & $31.5^{\mathrm{a}}$ & ND & 18.9 \\
\hline \multicolumn{3}{|c|}{ Response rate (\%) } & $70 \%$ & 50.1 & $47 \%$ & 12.8 \\
\hline
\end{tabular}

ND - no data;

a data from SHIP conducted in 1997-2001.

ple size in our own study was the highest. All observations were made among the inhabitants of cities (Wrocław, Oława, Szczecin, Police, Białystok, Lublin), and inhabitants of rural areas were included only in the Lublin survey. ${ }^{18}$ The average number of teeth in young seniors in Wrocław was similar to the average in Białystok (13.21 vs 13.36) and significantly higher than in Lublin (only 7.8 in persons over 60 years of age -7.0 in rural areas). ${ }^{18,19}$ The proportion of persons with remaining chewing function (> 20 teeth) was highest in West Pomeranian Voivodship (35.7\%), compared to 27.8 in Białystok and $21.3 \%$ in own research. ${ }^{19,20}$ The percentage of people with edentulism was by far the highest in the Lublin area (49.9\% in persons over 60 years of age), compared to $14.1 \%$ in Wrocław, $12.5 \%$ in Białystok, and $11.9 \%$ in West Pomeranian Voivodship. ${ }^{18-20}$ In Białystok, the average number of remaining teeth was noticeably higher in men and the proportion of edentulism was higher in women; ${ }^{19}$ in Wrocław these values were similar, although not statistically significant. In the Lublin area, the number of remaining teeth was significantly higher in men as well. ${ }^{18}$

The place of residence and education significantly influenced the number of remaining teeth in the area of Wrocław and Lublin (the protective effect of a large city and higher education). ${ }^{18}$ Some similarities related to dental caries were found in West Pomeranian Voivodship, the average DMFT index in persons treated exclusively in private facilities was 20.06 (D - 0.9, M - 9.7 and F - 9.43), compared to 16.4 in the Wrocław area (D - 0.88, M - 9.37 and $\mathrm{F}-6.29) .{ }^{20}$ The comparison of periodontal status between residents of Białystok and Wrocław indicates a rather worse condition in young seniors in the capital of Lower Silesia (BoP $36.2 \%$ vs $26.7 \%$, mean PD 2.55 vs 2.13 , CPI0 0\% vs $8.3 \%$, CPI3 + CPI4 $52.3 \%$ vs $40 \%) .{ }^{19}$

The oral hygiene status in the residents of both cities is equally bad (the proportion of persons who brush their teeth properly is $21 \%$ in Wrocław and $14.3 \%$ in Białystok; the proportion of persons who clean their interdental spaces properly is $7.4 \%$ in Wrocław and $12.7 \%$ in Białystok). In both cities, the periodontal status was generally worse in men, while in Wrocław it was more often at the level of statistical significance. The analysis of recent nationwide oral health surveys among persons aged 65 to 74 years in-

Table 8. Comparison of selected oral health behaviours among seniors in regional and national studies

\begin{tabular}{|c|c|c|c|c|c|c|}
\hline \multicolumn{3}{|c|}{ Study and year } & $\begin{array}{c}\text { Regular } \\
\text { dental appointment } \\
\text { (at least once a year) }\end{array}$ & $\begin{array}{c}\text { Regular } \\
\text { tooth brushing } \\
\text { (at least twice a day) }\end{array}$ & $\begin{array}{c}\text { Regular usage } \\
\text { of inter-dental care } \\
\text { devices (every day) }\end{array}$ & $\begin{array}{l}\text { Other } \\
\text { details }\end{array}$ \\
\hline \multirow{3}{*}{$\begin{array}{l}\text { National } \\
\text { studies }\end{array}$} & $\begin{array}{l}\text { Poland } \\
\text { 2013-2014 }\end{array}$ & $\begin{array}{c}N=807 \\
\text { age: } 65-74\end{array}$ & $78.2 \%$ & $76.2 \%$ & $17.2 \%$ & ND \\
\hline & $\begin{array}{l}\text { Germany }^{10} \\
2005\end{array}$ & $\begin{array}{c}N=787 \\
\text { age: } 65-74\end{array}$ & $88.8 \%$ & $80 \%$ & $41.7 \%$ & $\begin{array}{l}\text { electric toothbrush } \\
-18.3 \%\end{array}$ \\
\hline & $\begin{array}{c}U_{S A}^{50} \\
2009-2012\end{array}$ & $\begin{array}{c}N=897 \\
\text { age: } 65-74\end{array}$ & $76.3 \%$ & ND & $75 \%$ & $\begin{array}{l}\text { dental implants } \\
-5.1 \%, 0.13 \text { pro } \mathrm{p}\end{array}$ \\
\hline \multirow{4}{*}{$\begin{array}{l}\text { Regional } \\
\text { studies }\end{array}$} & $\begin{array}{c}\text { Wrocław Region } \\
2017\end{array}$ & $\begin{array}{c}N=333 \\
\text { age: } 65-74\end{array}$ & $68.4 \%$ & $71.7 \%$ & $18.9 \%$ & $\begin{array}{l}\text { dental implants } \\
-1.5 \%, 0.045 \text { pro } p\end{array}$ \\
\hline & $\begin{array}{c}\text { Pisa (Italy) })^{58} \\
2011\end{array}$ & $\begin{array}{l}N=350 \\
\text { age }>53\end{array}$ & $70 \%$ & $77 \%$ & $27 \%$ & $\begin{array}{l}\text { electric toothbrush } \\
-32 \%\end{array}$ \\
\hline & $\begin{array}{c}\text { Washington and Oregon }{ }^{59} \\
2008-2011\end{array}$ & $\begin{array}{l}N=368 \\
\text { age }>60\end{array}$ & ND & 63.3 & $79.9 \%$ & ND \\
\hline & $\begin{array}{c}\text { Carlos Barbosa (Brazil) })^{60} \\
2004\end{array}$ & $\begin{array}{l}N=388 \\
\text { age }>60\end{array}$ & $12.3 \%$ & $\begin{array}{c}82.9 \% \\
\text { (1 per day) }\end{array}$ & $56.4 \%$ & ND \\
\hline
\end{tabular}


dicates that there are notable differences between country regions, especially with regard to the number of remaining teeth and prevalence of edentulism.

Three comparable, most closely related foreign crosssectional studies in oral hygiene among young seniors were chosen (Table 7). Infection and Vascular Disease Epidemiology Study (INEST) was conducted in 1999-2003 among New Yorkers residing within Northern Manhattan. ${ }^{21}$ The examination was performed around maximum 28 teeth, at 6 assessment points (full-mouth estimates). Due to the significant racial differences, only data regarding Caucasian subjects was included in the analysis. Study of Health in Pomerania (SHIP) was conducted in Germany in 1997-2001 and 2008-2012, among racially homogeneous inhabitants of urban and rural areas in the north-eastern region of the country. ${ }^{22,23}$ The dental examination was performed around maximum of 14 teeth, at 4 assessment points (half-mouth recording). The Italian survey was conducted in 2009-2010 in line with a fullmouth protocol among 3-tier randomly selected group of Turin residents (northern Italy). ${ }^{24}$

Attention is drawn by low representativeness of own research. There is also a noticeable difference in the number of remaining teeth (from 10.6 to 20.6), the proportion of toothless persons ( 1 to $15.8 \%$ ), and the periodontal parameters such as prevalence of severe periodontitis according to CDC/AAP ranging from 14.3 to 51.3 in the examined population. Exposure to systemic (co-occurrence of cardiovascular and cerebrovascular diseases, diabetes, hypertension) and behavioral factors (nicotine and obesity) was similarly high in the compared populations. Poles still display the lowest level of oral hygiene procedures. The differences found in the study are probably partly due to differences in the methodology of dental examination, and the periodontal exponents are related to the number of remaining teeth. However, such notable gradients must also have other factors, e.g., socioeconomic.

In own observation, dental caries were the main medical cause of tooth loss $(81 \%$ of all teeth and an average of 12 teeth per patient were removed due to cariological indications). This regularity can be explained by the cohort effect related to people born in the 1940s, who for decades were exposed to "extraction dentistry" stemming from prevailing Eastern European theories of infection foci and incorrect behavior of medical personnel and health promoting behavior of the population. For example, in the national Hungarian study, the median $M$ in the DMFT index was 18.9 in the 65-74 age group and 9.07 in the $45-64$ age group. ${ }^{25}$ In the $21^{\text {st }}$ century, there is a visible global and local trend for the number of remaining teeth to increase and to reduce the proportion of edentulism. This is indicated by local cohort studies in young seniors, e.g., 5-year cohort study of Swedes from Orebro and Ostergotland from 1992-2012, or 5-year German cohort related to SHIP study in 2002-2006, and cross-sectional national research, e.g., the American study from 1957 to 2012 and the British one from 1988 and 2009. ${ }^{26-29}$ This is also confirmed by national Polish studies: the average number of teeth and the percentage of edentulism in the group of 811 Poles aged 65-74 years from all voivodships were 6.3 and $41.6 \%$, respectively, and in the group of 807 persons from 5 voivodships these values were at the level of 13.7 and $28.9 \% .^{30,31}$

This trend cannot be explained only by favorable changes in the main medical conditions: dental caries and periodontitis (the morbidity of periodontitis does not decline in the best case scenario!). Our study shows that the average number of remaining teeth was affected by the following factors (given in descending order of strength degree): personal income, type of dental treatment funding, education and place of residence. There were no statistically significant effects of gender, assessed systemic diseases and body weight. With respect to functional dentition, the influence of income, type of dental treatment funding, education, nicotine addiction, and place of residence was the strongest. There is a significant correlation between the prevalence of edentulism and personal income, type of dental treatment funding, education, and place of residence. Multivariate analysis models including confounders confirm our own observations. In the SHIP cohort study, the incidence of tooth loss was in a significant and most escalating relationship to current nicotine addiction, education period shorter than 10 years, fourth quartile of BMI, and the lowest personal income threshold (given in descending order). ${ }^{27} \mathrm{~A}$ Norwegian telephone survey showed that the number of remaining teeth amounting to at least 20 statistically was in the strongest relationship with regular dental appointments, highest personal income, complete abstinence from smoking, and living in the city. ${ }^{32}$ The probability of edentulism was significantly correlated with asthma, primary education and smoking in the past (income was defined by the level of wealth, quite diverse in the analyzed studies from 6 countries). ${ }^{33}$ Therefore, the social-economic gradient greatly influences the number of remaining teeth. The impact of income (personal or family) seems most clear, which is confirmed by a meta-analysis showing a cumulative odds ratio of 1.66 (with confidence interval of 1.48-1.86) only after it was adjusted for potential confounders in 8 contemporary surveys regarding the association between lowest income bracket and tooth loss. ${ }^{34}$ High income may indirectly affect the quality of dental treatment and tooth preservation strategies, and is linked, as a rule, to better education and more appropriate oral health behaviors (regular dental treatment, follow-up visits, greater availability of oral hygiene products). On the other hand, absence of own financial means for dental treatment restricts access to medical procedures (sometimes subjects seek only painreducing extraction) and exerts a negative psychological effect upon the decision to have a dental appointment. Using only private dental care allows patients to seek conservative dental treatment (in Polish conditions this 
may be endodontic treatment of back teeth, permanent prosthetic restorations, or periodontal surgery). Although own findings and the observations of other authors confirm the dependence of the dental status on education, the observed shift which sometimes occurs of such a relationship to a non-significant level together with adjusting for potential confounders (e.g., income, nicotine addiction, cleansing of interdental spaces) may indicate that the effect of educational gradient is not causal and works exclusively through other factors. ${ }^{26-28,32,33}$

Our findings and the observations of other authors confirm unequivocally the influence of tobacco addiction on the decline in the number of teeth. ${ }^{26,27,32,35,36}$ Gathered evidence indicates that the nature of this relationship is causal and does not depend on other factors. ${ }^{35}$ The strength of this relationship compound is moderate (greater in men), and there is a dose-response relationship. Biologically, the base of this relationship is the wellknown effect of nicotine upon periodontal supportive tissues and upon the development of dental caries and its fostering of microbiological shift towards periopathogens. The negative impact of former nicotine addiction on the number of teeth is also noticeable by comparison with non-smokers - in own studies former smokers had a significantly lower average number of teeth and they were more often diagnosed with tooth loss (below 10) also fully functional dentition was found less frequently. The risk of tooth loss due to nicotine addiction diminishes gradually, reaching a level comparable to non-smokers only after 20 years. ${ }^{36}$

Our studies show a higher number of teeth in men (13.65 vs 12.81 , prevalence of functional dentition higher by $4 \%$ ) and the proportion of edentulism higher by $5.3 \%$ in women. These differences were not statistically significant. The significance of these differences in contemporary studies of Białystok inhabitants aged 65 to 74 years has been shown by Sulewska et al. ${ }^{19}$ Polish national studies show a visible tendency to blur the gender impact on the number of teeth (in 2002 the average number of remaining teeth was higher by more than 2 in men, and the proportion of edentulism was higher by $7.6 \%$ in women; in 2014 the differences were 1.6 and $3 \%$, respectively). ${ }^{30,31}$ The findings of foreign authors are controversial in this regard, as some do not report any notable sexual dimorphism in terms of dental status while others prove it. ${ }^{24,27-29,33,37}$ This may indicate a regional specificity in this regard.

No significant link has been found between the number of teeth and the selected systemic diseases (diabetes, cardiovascular disease, myocardial infarction, stroke, osteoporosis, and hypertension) in the inhabitants of Wrocław. Presumably, this is due to the small sample size.

A notable influence of diabetes upon the number of teeth was shown in the population of over 70,000 American diabetics aged more than 65 years. ${ }^{38}$ The important relationship between the number of remaining teeth and mortality, irrespective of medical, social and economic factors, was determined by observing 4 cohorts of over 1,800 Swedes aged over 70 years. ${ }^{39}$ The findings regarding tooth loss as an independent weak risk factor for stroke was made on the basis of a survey of more than 13,000 Americans aged over 60 years..$^{40}$

In young seniors in Wrocław, no meaningful relationship was found between body mass expressed by BMI index and number of teeth. This is consistent with the observations of the Brazilian authors. ${ }^{41}$ Also, Ostberg et al. did not observe any significant relationship between tooth loss and general and abdominal obesity in individuals over 60 years of age. ${ }^{42}$

The DMFT index for the whole group of young seniors in Wrocław is 17.45 , and the main component determining its height is the cariologic extraction, with an average of 12 teeth per person. Only 1 reference point has been found in the available contemporary Polish literature: DMFT value 16.31 (DT 2.95, MT 10.91 and FT 2.45) in a regional study of men from Białystok. ${ }^{43}$ The comparison with an analogous indicator of dental caries in males from Wrocław shows a similarly high frequency of tooth removal due to caries, a lower number of teeth with ongoing disease, and twice as many filled teeth. The comparison of the DMFT index of the last 5 national German studies for this age group (17.7: DT 0.5, MT 11.1 and FT 6.1) indicates better control and treatment of caries in German seniors. ${ }^{44}$ The lowest DMFT index values in own studies were shown in individuals with the highest personal income -16.12 , and in persons treated exclusively in private practices - 16.4 (in this group the number of filled teeth is also the highest -6.1 ). The effect of the socioeconomic gradient on the indicators of caries was confirmed. Another significant element was the increasing influence of male gender, living in a small town and an active (and former, in the case of the number of fillings) tobacco addiction upon the indicators of caries. In a systematic contemporary review of the literature on nicotine-carcinogenicity, only 1 study was conducted among the elderly who had a significantly higher DMFT index value at the age of 75, and MS value in current smokers by comparison to persons who have never smoked at the age of 65 and $75 .{ }^{45}$ One of the factors that may aggravate the development of caries (also in root) in the elderly may be the effect of polypragmia causing reduced saliva secretion.

In own research the full-mouth estimates methodology was used with a modification of 4 assessment points. It is now considered to be the gold standard for epidemiological study of periodontal condition, and it allows for referring to the definition of periodontitis based on PD and CAL measurements. This methodology has been proposed in the USA and currently it is used exclusively in epidemiological studies, whereas in Europe it is only now introduced. ${ }^{16,17,21,24,46}$ Eke et al. have shown that the use of a periodontal examination protocol other than a comprehensive oral examination may lead to underestimating the morbidity of periodontitis even by $50 \% .^{16}$ 
In our study, the negative effect of male gender (higher average PD, the proportion of persons with $\mathrm{PD}>5 \mathrm{~mm}$, lower proportion of males with CPI1 and higher with CPI4) and current nicotine addiction (higher average PD, higher proportion of persons with $\mathrm{PD}>5 \mathrm{~mm}$, higher proportion of persons with CAL $\geq 3 \mathrm{~mm}$, lower average number of sextants with CPI0, higher average number of sextants with CPI4, more frequent occurrences of periodontitis according to $\mathrm{CDC} / \mathrm{AAP}$ ) upon periodontium was confirmed. These are the standard risk factors for periodontal inflammation and they are generally found to be consistent in contemporary literature on both regional, but primarily on national research. ${ }^{10,22,31,46-49}$ More controversial is the influence of sexual dimorphism upon the morbidity of periodontitis in people over 65 years old. There are few observations that do not confirm the worse clinical condition of male seniors. ${ }^{24}$ Eke et al. in recent American national studies have observed the differential blurring of differences among sexes in periodontitis prevalence as defined by the CDC/AAP, which has been explained by the postmenopausal condition of women, when estrogen deficiency increases destructive processes within the periodontium. ${ }^{46}$ It should be borne in mind that the negative impact of the male gender may result from other factors associated with it, such as more frequent tobacco addiction or considerably worse oral hygiene (confirmed by own studies). The impact of the current tobacco addiction upon the development and clinical course of periodontitis is clear and strong. In our own observations, this was the only factor closely related to severe periodontitis according to the CDC/AAP. There is general agreement as to the causal nature of existing nicotine addiction in the development of periodontitis (the compatibility of many studies, the moderate strength of the dose-response effect, reversibility). Particularly important is the information on the fast disappearance of the negative effects of nicotine on the periodontium after quitting,which strengthens the importance of minimal anti-nicotine intervention in the secondary prevention of periodontal inflammation. ${ }^{50}$ Particularly dangerous for the periodontium is the persistence of nicotine addiction in postmenopausal women, in whom its interaction with osteoporosis exerts a synergistic effect on the resorption of alveolar bone. ${ }^{46}$ In the future, a gradual improvement in the condition of the periodontium should be expected, resulting from the decline of the population of tobacco addicts (most frequently the elderly quit smoking after a sudden medical event).

The strength of the link between periodontal disease and systemic diseases is most often poor, at the limit of importance after adjusting the risk for confounding, which is particularly true for the elderly population due to frequent co-morbidity. The meta-analysis of 5 cohort studies involving 86,092 people indicated a significant increase in the risk of developing coronary heart disease during periodontitis, but only by $14 \% .^{51}$
Dietrich et al. analyzed 12 or more cohort and clinical control studies and reported weak or moderate (risk score was generally not greater than 2) strength of the relationship between periodontitis and incidents of atherosclerotic cardio-cerebrovascular disease, which was attenuated to irrelevant in people over 65 years of age. ${ }^{52}$ In this context, it is understood that there is no significant relationship between the periodontal status and systemic diseases analyzed in the elderly population in Wrocław. The only exception were more frequent extractions of teeth due to periodontal indications in patients with previous myocardial infarction or stroke (which should not be negatively assessed). The absence of a notable association with periodontal indicators was also related to the most common disease in the studied population - hypertension (only 78 out of 160 hypertension cases were included in the study, as the remaining ones co-existed with the assessed systemic diseases). The observation of the rare occurrence of severe periodontitis according to CDC/AAP in this group of individuals appears to be accidental. Opinions on the relationship between oral health and hypertension are divergent. The meta-analysis of 12 cross-sectional studies, including those adjusted for confounder risk measures, indicated a considerable $16 \%$ increase in risk of hypertension occurrence in the presence of periodontitis. ${ }^{53}$ In contrast, in a 9-year cohort study of 5,895 subjects aged 65 years and over, no significant correlation was found between the dental parameter and hypertension. ${ }^{54}$ In own assessment, no statistically significant relationship between periodontal condition and body weight was observed. This is in line with other authors' observations. ${ }^{2,47,50,55}$ Even in the meta-analysis which shows a significant relationship between clinical indicators of periodontitis and obesity, it is observed that in the elderly this relationship is weaker, which is associated with the inability to control all factors that interfere with these observations (diabetes, metabolic syndrome, nicotine, gender, oral hygiene). ${ }^{56}$

In own analysis, socioeconomic factors, beside their influence upon extraction decisions due to periodontal indications, were not significantly related to clinical parameters and periodontal diagnoses in line with CPI and CDC/AAP. This observation is in opposition to the findings of most national studies. ${ }^{46-50}$ This is particularly evident in American studies, where, apart from classical factors in the form of income and education, very diverse racial-ethnic factors come into play, even along with marital status (with biggest negative impact upon the divorced) and the frequency of dental appointments, with worse condition of the periodontium in more often treated subjects. ${ }^{16,46,50}$ The latter seemingly astonishing observation stems from the fact that American seniors seek periodontal treatment. This has also become evident in recent national German studies reporting an increasing tendency among young seniors to seek periodontal, implant and prosthetic treatment using fixed restorations. ${ }^{57}$ 
The elderly in the urban area of Wrocław declare that pain is their main reason to seek dental treatment, and periodontal problems are the reason for only $3 \%$ of the cases. In this respect, the impact of the cohort effect as well as the relatively low economic gradient among Polish retirees may be significant.

Of the 131 cases diagnosed with clinical pathology of oral mucosa, $38.9 \%$ are cancer and pre-cancer lesions. Out of all reported pathological lesions, $42.7 \%$ require immediate treatment. These observations prove the need for examining oral mucosa during every dental appointment. With regard to the nationwide Polish study among subjects of this age, attention is drawn to the greater prevalence of denture stomatitis and fewer occurrences of leukoplakia and oral mycosis. ${ }^{31}$

It is important to emphasize the very poor oral hygiene in the examined group of older people in the Wrocław urban area. Even worse results were reported in a regional study of young seniors in Białystok (average PI is 50.8 vs 57.8 , and average API is 66.7 vs $60 \%) .{ }^{19}$ Considerably worse result for brushing (the highest PI values) in Wrocław appeared in the following order: persons with lowest income, current nicotine users, small town residents, persons treated solely in national healthcare facilities, men and persons with primary education. For cleaning interdental spaces (highest average API), the order was as follows: persons with lowest income (average API 81.5!), current smokers, men, and persons treated solely in national healthcare facilities. These observations confirm the well-known claim about the close link between poor oral hygiene and low socioeconomic status, male gender, tobacco dependence, and place of residence away from bigger towns. Also, the health promoting behaviors of the people we examined are unsatisfactory (pain is still the main reason to make a dental appointment; almost one third of the subjects only occasionally make dental appointments). The comparison of selected oral health related behaviors of the elderly with foreign regional surveys and national research is presented in Table $8 .^{10,31,50,58-60}$ Basically, it is concluded by comparison that the awareness of Polish young seniors of the need to clean interdental spaces, that is to perform a prophylactic procedure extremely important in caries and periodontitis prevention, is the lowest. Americans lead in cleaning interdental spaces and Germans have dental appointments most regularly - currently $90 \%$ of dental patients make appointments to check oral health.

Our research is limited in numerous ways and these limitations demand caution in making generalizations. The first is the elderly's low response to the invitations, which determines their low representativeness in the examination. The second is the inherent feature of a typical cross-sectional study that did not resolve the temporal relationship between 2 medical events. The third limitation is the fact that many variables (especially these related to general health) were determined anamnestically with a risk of error for temporally distant events such as the question about the cause for tooth removal in the past. Another limitation results from the fact that the study was conducted solely in the urban environment, with the exclusion of the countryside areas, which could also influence the evaluation of oral health. The impact of other variables not yet deemed as risk factors, but potentially able to affect oral health, e.g., diet, physical activity or marital status, has not been taken into account. Finally, for full compliance with the protocol for comprehensive dental examination, 2 measurement points on lingual surfaces of teeth were evaluated.

The conducted regional cross-sectional epidemiological study has shown an increase in the number of remaining teeth in young seniors in Wrocław despite no significant improvement in the incidence of dental caries and periodontitis. The influence of classical risk factors for tooth loss and periodontitis has been confirmed, with the exception of significant associations with analyzed systemic diseases, which resulted probably from the sample size. The population is characterized by low dental treatment requirements and poor habits related to oral health. Targeted regional preventive and intervention programs have to emerge from representative epidemiological studies taking into account the impact of as many variables as possible. Cohort studies - not yet conducted - would definitely deepen this knowledge. Special emphasis should be placed on the ultimate definition of the possible causal nature of the impact of social-economic factors on oral health.

\section{References}

1. Thomson WM. Epidemiology of oral health conditions in older people. Gerodontol. 2014;31(Suppl. 1):9-16.

2. Zalega T. Segment of people aged $65+$ in Poland. Quality of life, consumption, consumer behavior. Warszawa: Wydawnictwo Naukowe Wydziału Zarządzania Uniwersytetu Warszawskiego; 2016 [in Polish].

3. Marcenes W, Kassebaum NJ, Bernabe E, et al. Global burden of oral conditions in 1990-2010: A systemic analysis. J Dent Res. 2013;92:592-597.

4. Kassebaum NJ, Bernabe E, Dahiya M, Bhandari M, Murray CJL, Marcenes W. Global burden of severe tooth loss: A systemic review and meta-analysis. J Dent Res. 2014;93:20-28.

5. Stock C, Jürges H, Shen J, Bozorgmehr K, Listl S. A comparison of tooth retention and replacement across 15 countries in the over50s. Community Dent Oral Epidemiol. 2016;44:223-231.

6. Frencken JE, Sharma P, Stenhouse L, Green D, Laverty D, Dietrich T. Global epidemiology of dental caries and severe periodontitis - A comprehensive review. J Clin Periodontol. 2017;44(Suppl. 18):S94-S105.

7. Kassebaum NJ, Bernabe E, Dahiya M, Bhandari M, Murray CJL, Marcenes W. Global burden of severe periodontitis in 1990-2010: A systemic review and metaregression. J Dent Res. 2014;93:1045-1053.

8. Kassebaum NJ, Bernabe E, Dahiya M, Bhandari M, Murray CJL, Marcenes W. Global burden of untreated caries: A systemic review and metaregression. J Dent Res. 2015;94:650-1053.

9. Persson GR, Mancl LA, Martin J, Page RC. Assessing periodontal disease risk. A comparison of clinicians' assessment versus a computerized tool. JADA. 2003;134:575-582.

10. Holtfreter B, Kocher T, Hoffmann T, Desvarieux M, Micheelis W. Prevalence of periodontal disease and treatment demands based on a German dental survey (DMS IV). J Clin Periodontol. 2010;37:211-219.

11. Konopka T, Zawada $Ł$, Kobierzycka A, Chrzęszczyk D. Periodontal condition in 35-44 and 65-74 year-old residents from Lower Silesia Region. Dent Med Probl. 2015;52:447-454 [in Polish]. 
12. O'Leary TJ, Drake RB, Naylor JE. The plaque control record. J. Periodontol. 1972;43:38.

13. Lange DE, Plagmann H-C, Eenboom A, Promesberger A. Klinische Bewertungsverfahren zur Objektivierung der Mundhygiene. Dtsch Zahnärztl Z. 1977;32:44-49 [in German].

14. Ainamo J, Bay I. Problems and proposals for recording gingivitis and plaque. Int Dent J. 1975;25:229-235.

15. Dhingara K, Vandana KL. Indices for measuring periodontitis: A literature review. Int Dent J. 2011;61:76-84.

16. Eke PI, Dye BA, Weil L, Thornton-Evans GO, Genco RJ. Prevalence of periodontitis in the United States: 2009 and 2010. J Dent Res. 2012;91:914-920.

17. Page RC, Eke PI. Case definitions for use in population-based surveillance of periodontitis. J Periodontol. 2007;78(Suppl 7):1387-1399.

18. Panasiuk L, Kosiniak-Kamysz W, Horoch A, Paprzycki P, Karwat D. Tooth loss among adult rural and urban inhabitants of the Lublin Region. Ann Agric Environ Med. 2013;20:637-641.

19. Sulewska M, Pietruski J, Sulima E, et al. Periodontal status of Bialystok citizens aged 65-74 years: A pilot study. Dent Med Probl. 2017;54:173-178.

20. Wilczyński $Ł$. Comparing prosthetic status and need for prosthetic treatment of tooth loss in patients aged 56-74 years in the Western Pomerania Region depending on the source of financing. Pomeranian J Life Sci. 2017;63:56-62 [in Polish].

21. Desvarieux M, Demmer RT, Jacobs DR, et al. Periodontal bacteria and hypertension: The Oral Infections and Vascular Disease Epidemiology Study (INVEST). J Hypertens. 2010;28:1413-1421.

22. Holtfreter B, Demmer RT, Bernhardt O, et al. A comparison of periodontal status in the two regional, population-based studies of SHIP and INVEST. J Clin Periodontol. 2012;39:1115-1124.

23. Schützhold S, Kocher T, Biffar R, et al. Changes in prevalence of periodontitis in two German population-based studies. J Clin Periodontol. 2015;42:121-130.

24. Aimetti M, Perotto S, Castiglione A, Mariani GM, Ferrarotti F, Romano F. Prevalence of periodontitis in an adult population from an urban area in North Italy: Findings from a cross-sectional population-based epidemiological survey. J Clin Periodontol. 2015;42:622-631.

25. Madlena M, Hermann P, Jahn M, Fejedry P. Caries prevalence and tooth loss in Hungarian adult population: Results of national survey. BMC Public Health. 2008;8:364.

26. Åstrøm AN, Gülcan F, Ekbäck G, Ordell S. Long-term healthy life style patterns and tooth loss studied in a Swedish people of middle aged and older people. Int J Dent Hyg. 2015;13:292-300.

27. Buchwald S, Kocher T, Biffar R, Harb A, Holtfreter B, Meisel P. Tooth loss and periodontitis by socio-economic status and inflammation in a longitudinal population based study. J Clin Periodontol. 2013;40:203-211.

28. Slade GD, Akinkube AA, Sanders AE. Projections of U.S. edentulism prevalence following 5 decades of decline. J Dent Res. 2014;93:959-965.

29. Bernabé E, Sheiham A. Tooth loss in the United Kingdom - Trends in social inequalities: An age-period-and-cohort analysis. PloS One. 2014;9:(8):e104808.

30. Jodkowska E. The condition of dentition status of adult Polish citizens in years 1998-2009. Przegl Epidemiol. 2010:64:571-576 [in Polish].

31. Konopka T, Dembowska E, Pietruska M, Dymalski P, Górska R. Periodontal status and selected parameters of oral condition of Poles aged from 65 to 74 years. Przegl Epidemiol. 2015;69:643-647.

32. Haugejorden O, Klock KS, Åstrøm AN, Skaret E, Trovik TA. Socioeconomic inequality in the self-reported number of natural teeth among Norwegian adults - An analytical study. Community Dent Oral Epidemiol. 2008;36:269-278.

33. Pelzer K, Hewlett S, Yawson AE, et al. Prevalence of loss of all teeth (edentulism) and associated factors in older adults in China, Ghana, India, Mexico, Russia and South Africa. Int J Environ Res Public Health. 2014;11:11308-11324.

34. Seering LM, Nascimento GC, Peres MA, Horta BL, Demarco FF. Tooth loss in adults and income: Systemic review and meta-analysis. J Dent. 2015;43:1051-1059.

35. Hanioka T, Ojima M, Tanaka K, Matsuo K, Sato F, Tanaka H. Causal assessment of smoking and tooth loss: A systemic review of observational study. BMC Public Health. 2011;11:221.

36. Dietrich T, Walter C, Oluwagbemigun K, et al. Smoking, smoking cessation and risk of tooth loss: The EPIC-Potsdam study. J Dent Res. 2015;94:1369-1375.
37. Ribeiro CG, Cascaes AM, Ribeiro Silva $A E$, et al. Edentulism, severe tooth loss and lack of functional dentition in elders: A study in Southern Brazil. Braz J Dent. 2016;27:345-342.

38. Huang DL, Chan KWG, Young BA. Poor oral health and quality of life in U.S. older adults with diabetes. J Am Geriatr Soc. 2013;61:1782-1788. doi 10.1111/jgs.12452.

39. Österberg T, Carlsson GE, Sundh V, Mellström D. Number of teeth - A predictor of mortality in 70-year-old subjects. Community Dent Oral Epidemiol. 2008;36:258-268.

40. Wiener RC. Tooth loss and stroke: Result from the Behavioral Risk Factor Surveillance System, 2010. J Dent Hyg. 2014;88:285-291.

41. Sing A, Peres MA, Peres KG, de Oliveira Bernardo C, Xavier A, D'Oris E. Gender differences in the association between tooth loss and obesity among older adults in Brazil. Rev Saude Publ. 2015;49:44.

42. Ostberg AL, Nyholm M, Gullberg B, Rästam L, Linblad U. Tooth loss and obesity in a defined Swedish population. Scand J Public Health. 2009;37:427-433.

43. Szpak A, Stokowska W, Gołębiewska E. Dentition status and treatment needs of 65-74-year-old men living in Bialystok. Probl Hig Epidemiol. 2012;93:97-104 [in Polish].

44. Lopez R, Smith PC, Göstemeyer G, Schwendicke F. Ageing, dental caries and periodontal diseases. J Clin Periodontol. 2017;44(Suppl. 18):145-152.

45. Benedetti G, Campus G, Strohmenger L, Lingström P. Tobacco and dental caries: A systematic review. Acta Odontol Scand. 2013;71:363-374.

46. Eke PI, Wei L, Thornton-Evans GO, et al. Risk indicators in US adults: NHANES 2009 to 2012. J Periodontol. 2016;87:1174-1185.

47. Kongstad J, Enevold C, Chistensen LB, Fiehn NE, Holmstrup P. Impact of periodontitis case criteria: A cross-sectional study of lifestyle. J Periodontol. 2017;88; 602-609.

48. Carasol M, Llodra JC, Fernandez-Meseguer A, et al. Periodontal conditions among employed adults in Spain. J Clin Periodontol. 2016:43:548-556.

49. Hermann P, Gera I, Borbély J, Fejérdy P, Madléna M. Periodontal health of an adult population in Hungary: Findings of a national survey. J Clin Periodontol. 2009;36: 449-457.

50. Eke PI, Wei L, Borgnakke WS, et al. Periodontal prevalence in adults $\geq 65$ years ago in the USA. Periodontol 2000. 2016;72:76-95.

51. Bahekar AA, Singh S, Saha S, Molnar J, Arora R. The prevalence and incidence of coronary heart disease is significantly increased in periodontitis: A meta-analysis. Am Heart J. 2007;154:830-837.

52. Dietrich $T$, Sharma $P$, Walter $C$, Weston $P$, Beck J. The epidemiological evidence behind the association between periodontitis and incident atherosclerotic cardiovascular disease. J Periodontol. 2013;84(Suppl. 4):S70-S84

53. Martin-Cabazas R, Seelam N, Petit C, et al. Association between periodontitis and arterial hypertension: A systemic review and meta-analysis. Am Heart J. 2016;180; 98-112.

54. Darnaud Ch, Thomas F, Pannier B, Danchin N, Bouchard P. Oral health and blood pressure the PC cohort. Am J Hyperten. 2015;28:1257-1261.

55. Oikarinen R, Myrjala A-MH, Komulainen $\mathrm{K}$, et al. Body mass index and periodontal infection in a sample of non-smoker older individuals. Oral Dis. 2014;20:e20-e25.

56. Chaffee BW, Weston SJ. Association between chronic periodontal disease and obesity: A systematic review and meta-analysis. J Periodontol. 2010;81:1708-1724.

57. Jordan R, Micheelis W. Fünfte Deutsche Mundgesundheitsstudie (DMS V) - Kurzfassung. Köln: Institut der Deutschen Zahnärzte; 2015 [in German].

58. Vano M, Gennai S, Karapetsa D, et al. The influence of educational level and oral hygiene behaviours on DMFT index and CPITN index in an adult Italian population: An epidemiologic study. Int J Dent Hyg. 2015;13:151-157.

59. Rothen M, Cuna-Cruz J, Zhou L, Mancl L, Jones JS, Berg J. Oral hygiene behaviours and caries experience in northwest PRECEDENT patients. Community Dent Oral Epidemiol. 2014;42:526-535.

60. De Marchi RJ, Hilgert JB, Hugo FN, dos Santos CM, Martins AB, Padilha DM. Four-year incidence and predictors of tooth loss among older adults in a southern Brazilian city. Community Dent Oral Epidemiol. 2012;40:396-405. 